\title{
Contemporary open aortic arch repair with selective cerebral perfusion in the era of endovascular aortic repair
}

\author{
Yutaka Iba, MD, ${ }^{\text {a }}$ Kenji Minatoya, $\mathrm{MD}, \mathrm{PhD},{ }^{\mathrm{a}}$ Hitoshi Matsuda, $\mathrm{MD}, \mathrm{PhD},{ }^{\mathrm{a}}$ Hiroaki Sasaki, MD, $\mathrm{PhD},{ }^{\mathrm{a}}$ \\ Hiroshi Tanaka, MD, PhD, ${ }^{\mathrm{a}}$ Junjiro Kobayashi, $\mathrm{MD}, \mathrm{PhD},{ }^{\mathrm{a}}$ and Hitoshi Ogino, $\mathrm{MD}, \mathrm{PhD}^{\mathrm{b}}$
}

Objective: With the recent advance of endovascular aortic repair, conventional open repair for aortic arch lesions should be reassessed. We reviewed our contemporary open arch repair with selective antegrade cerebral perfusion by way of the axillary artery with deep or moderate hypothermia.

\begin{abstract}
Methods: From 2001 to 2011, 1007 patients (median age, 72 years) underwent open arch repair with selective cerebral perfusion through the right axillary artery and hypothermic circulatory arrest: deep $\left(<25^{\circ} \mathrm{C}\right)$ in $48 \%$ and moderate $\left(25^{\circ}-28^{\circ} \mathrm{C}\right)$ in $52 \%$. Of the 1007 patients, $73 \%$ underwent total arch replacement and $26 \%$ emergent surgery for aneurysm rupture or acute aortic dissection.
\end{abstract}

\begin{abstract}
Results: The early mortality was $4.7 \%$ for all patients. Permanent and temporary neurologic dysfunction occurred in $3.5 \%$ and $6.7 \%$, respectively. No spinal cord injury occurred, even with moderate hypothermia. The independent predictors of in-hospital mortality included chronic obstructive pulmonary disease, liver dysfunction, chronic kidney disease, and concomitant coronary artery bypass. The independent predictors of permanent neurologic dysfunction included cerebrovascular disease, emergency surgery, and concomitant coronary artery bypass. The cumulative survival rate was $80.4 \%$ and $71.2 \%$ at 5 and 8 years, respectively. Freedom from reoperation related to the initial arch repair was $98.0 \%$ and $96.9 \%$ at 5 and 8 years, respectively.
\end{abstract}

Conclusions: Conventional open arch repair yielded satisfactory outcomes and should remain the standard therapy, with good long-term durability in all but high-risk patients. (J Thorac Cardiovasc Surg 2013;145:S72-7)

Open surgical repair for aortic arch aneurysm is associated with considerable mortality and morbidity, especially stroke. However, its outcome has been dramatically improved by innovations in surgical technique, including brain protection, in the past 2 decades. In particular, the widespread use of antegrade selective cerebral perfusion (SCP) for cerebral protection has contributed to the reduction in mortality and stroke rate. ${ }^{1-4}$ However, thoracic endovascular aortic repair (TEVAR) has been recognized as an alternative therapeutic option for thoracic aortic aneurysm, and it has been attempted, mainly for high-risk patients. Although this new technology was initially applied for descending aortic aneurysm, its adoption has extended to complex aortic arch lesions, predominantly in conjunction with several debranching techniques of the arch vessels as a less-invasive alternative: hybrid TEVAR. ${ }^{5,6}$ Thus, contemporary open arch repair needs to be reassessed as

From the Department of Cardiovascular Surgery, ${ }^{\mathrm{a}}$ National Cerebral and Cardiovascular Center, Suita, Osaka, Japan; and Department of Cardiovascular Surgery, Tokyo Medical University, Shinjuku-ku, Tokyo, Japan.

Disclosures: Drs Iba, Minatoya, Matsuda, Sasaki, Tanaka, Kobayashi, and Ogino have nothing to disclose with regard to commercial support.

Presented at the American Association for Thoracic Surgery Aortic Surgery Symposium 2012, April 26-27, 2012, New York, NY.

Received for publication April 26, 2012; revisions received Aug 13, 2012; accepted for publication Nov 20, 2012; available ahead of print Dec 26, 2012.

Address for reprints: Yutaka Iba, MD, Department of Cardiovascular Surgery, National Cerebral and Cardiovascular Center, 5-7-1 Fujishiro-dai, Suita, Osaka 565-8565, Japan (E-mail: iba@hsp.ncvc.go.jp).

$0022-5223 / \$ 36.00$

Copyright (c) 2013 by The American Association for Thoracic Surgery http://dx.doi.org/10.1016/j.jtcvs.2012.11.047 a benchmark for consideration of the optimal therapeutic strategy for aortic arch aneurysm. In the present study, the results with our well-established contemporary open arch repair procedure during the past decade-with sophisticated SCP by way of right axillary artery (RAxA) perfusion and hypothermic circulatory arrest (HCA) — were reviewed.

\section{PATIENTS AND METHODS}

From April 2001 to September 2011, 1007 consecutive patients underwent open aortic arch repair at the National Cerebral and Cardiovascular Center, Japan. The inclusion criteria included an approach through a median sternotomy, the use of SCP with HCA, and hemi- or partial or total prosthetic replacement of the aortic arch. The patient characteristics are listed in Table 1 . The median age was 72 years, and $66.3 \%$ of patients were men. The present cohort included 30 patients $(3.0 \%)$ who had a connective tissue disorder such as the Marfan or Loeys-Dietz syndrome. Of the 1007 patients, $33(3.3 \%)$ had a history of previous cardiac surgery and 38 $(3.8 \%)$ had undergone previous aortic surgery of the aortic root, ascending aorta, or aortic arch. Aortic pathologic features included acute type A aortic dissection in 230 patients $(22.8 \%)$. Emergency operations were performed in 259 patients $(25.7 \%)$, including $76(7.5 \%)$ with shock.

The surgical variables are listed in Table 2 . In most patients $(73.1 \%)$, total arch replacement (TAR) was performed. Concomitantly, coronary artery bypass grafting $(\mathrm{CABG})$ was performed in 186 patients $(18.5 \%)$ and root replacement in $59(5.9 \%)$.

Data were collected from the medical records for the patients who were followed up in our outpatient department. The data for the others were investigated by telephone or mail. The follow-up rate was $93.0 \%$. The mean follow-up period was $44.9 \pm 33.7$ months, with a maximum of 128 months. The institutional review board of our center approved the present retrospective study and waived patient consent on the condition that the patients were not identified. 

Abbreviations and Acronyms
$\mathrm{CABG}=$ coronary artery bypass grafting
$\mathrm{CKD}=$ chronic kidney disease
COPD = chronic obstructive pulmonary disease
CVD = cerebrovascular disease
HCA = hypothermic circulatory arrest
PND = permanent neurologic dysfunction
$\mathrm{RAxA}=$ right axillary artery
SCP = selective cerebral perfusion
TAR = total arch replacement
TEVAR $=$ thoracic endovascular aortic repair

a forced expiratory volume less than $70 \%$ of the normal value or daily use of a bronchodilator. Liver dysfunction was defined as a serum transaminase level more than twice the normal value or a total bilirubin level greater than $2.0 \mathrm{mg} / \mathrm{dL}$. CKD was defined as a serum creatinine level greater than $1.5 \mathrm{mg} / \mathrm{dL}$ or a requirement for hemodialysis.

\section{Statistical Analysis}

Continuous data are presented as the mean \pm standard deviation. Multivariate stepwise logistic analysis was used to identify independent predictors for early mortality and PND. The predictive factors with $P \leq .1$ on univariate analysis were used for subsequent multivariate analysis. The results are presented as the odds ratios and $95 \%$ confidence intervals. Cumulative survival and freedom from reoperation rates were calculated using the Kaplan-Meier methods. All statistical analyses were performed using SPSS software (IBM SPSS Inc, Chicago, Ill).

\section{RESULTS}

The overall early mortality, including 30-day and in-hospital deaths, was $4.7 \%$. It was $5.0 \%$ even for the emergency cases. The cause of early death was low output syndrome in 16 patients $(34.0 \%)$, sepsis in 15 patients $(31.9 \%)$, respiratory failure in 10 patients $(21.3 \%)$, rupture of residual aneurysm in 3 patients $(6.4 \%)$, and intestinal ischemia in 3 patients $(6.4 \%)$. On multivariate analysis, the independent risk factors for early mortality were COPD $(P=.041)$, liver dysfunction $(P=.014)$, CKD $(P<.001)$, and concomitant CABG $(P<.001$; Table 3$)$.

Cerebral deficits developed in 102 patients $(10.2 \%)$ postoperatively, including PND in 35 patients $(3.5 \%)$ and transient neurologic dysfunction in $67(6.7 \%)$. No spinal cord injury occurred in any patient. The multivariate analysis showed that the independent predictors for PND were CVD $(P=.002)$, emergency surgery $(P<.001)$, and concomitant CABG $(P=.006$; Table 4$)$.

Prolonged ventilation - for more than 72 hours-was required for 146 patients $(14.5 \%)$. The length of stay in the intensive care unit and duration of postoperative hospitalization was 3 days (interquartile range, 2-6 days) and 25 days (interquartile range, 19-35 days), respectively.

During the follow-up period, there were 140 late deaths $(14.6 \%)$. Of these, 13 were aorta-related deaths, including rupture of a descending thoracic aneurysm in 5 , an abdominal aortic aneurysm in 5 , and sudden death in 3 . Of the 10 patients with aneurysm rupture, regular examinations at the hospital had been suspended for 5 , and the remaining 5 patients had been observed medically because of their condition or their wish. Cardiac-related deaths occurred in 25 patients $(17.9 \%)$, including congestive heart failure in 14 , acute myocardial infarction in 8, and arrhythmia in 3. Other nonaorticor noncardiac-related deaths occurred as follows: respiratory failure in 28 patients $(20.0 \%)$, cancer in $21(15.0 \%)$, cerebrovascular accident in $16(11.4 \%)$, sepsis in $10(7.1 \%)$, gastrointestinal complications in $5(3.6 \%)$, renal failure in $4(2.9 \%)$, accidents in $4(2.9 \%)$, senility in $7(5.0 \%)$, and unknown in $7(5.0 \%)$. The cumulative survival was $80.4 \%$ and $71.2 \%$ at 5 and 8 years, respectively (Figure 1 ). 
TABLE 1. Patient characteristics $(n=1007)$

\begin{tabular}{lc}
\hline \multicolumn{1}{c}{ Characteristic } & Value \\
\hline Age $(\mathrm{y})$ & \\
Median & 72 \\
Range & $12-93$ \\
Male gender & $668(66.3 \%)$ \\
Hypertension & $828(82.2 \%)$ \\
Diabetes & $149(14.8 \%)$ \\
Hyperlipidemia & $381(37.8 \%)$ \\
Smoking & $221(21.9 \%)$ \\
Cerebrovascular disease & $124(12.3 \%)$ \\
Coronary artery disease & $280(27.8 \%)$ \\
Ejection fraction $<30 \%$ & $14(1.4 \%)$ \\
COPD & $116(11.5 \%)$ \\
Liver dysfunction & $16(1.6 \%)$ \\
CKD (creatinine $\geq 1.5$ mg/dL) & $104(10.3 \%)$ \\
Patients with CKD requiring hemodialysis & 16 \\
Connective tissue disorder & $30(3.0 \%)$ \\
Marfan syndrome & 25 \\
Loeys-Dietz syndrome & 5 \\
Aortitis & $23(2.3 \%)$ \\
Previous cardiac surgery & $33(3.3 \%)$ \\
Aortic redo surgery & $38(3.8 \%)$ \\
Shock & $76(7.5 \%)$ \\
Emergency & $259(25.7 \%)$ \\
Acute dissection & $230(22.8 \%)$ \\
\hline COPD, Chronic obstructive pulmonary disease; $C K D$, chronic kidney & disease. \\
&
\end{tabular}

Late aortic operations related to the previously repaired arch segment were required for false aneurysm of the anastomotic site in 12 patients and for graft infection in 2 . Of the patients with false aneurysms at the distal anastomotic site, 8 underwent TEVAR. Four patients who developed false aneurysms at the proximal anastomotic site and two who developed graft infection underwent redo graft replacement of the aortic arch. Freedom from reoperation for the initially repaired arch segment was $98.0 \%$ and $96.9 \%$ at 5 and 8 years, respectively (Figure 2, A). Other late aortic reoperations unrelated to the initial aortic arch replacement included composite graft replacement in 6, valve-sparing root replacement in 2 , completion arch replacement after hemiarch repair in 5, descending aortic replacement in 36, thoracoabdominal aortic replacement in 28 , abdominal aortic repair in 59, and endovascular repair of the descending aorta in 46 and the abdominal aorta in 10 patients. Freedom from all late aortic reoperations at 5 and 8 years was $78.0 \%$ and $71.7 \%$, respectively (Figure $2, B$ ).

\section{DISCUSSION}

Open aortic arch repair remains challenging, with some difficulties. In most patients, the etiology of the arch aneurysm is atherosclerosis; therefore, most of patients are quite elderly and have many atherosclerotic lesions. However, recent advances in brain protection, surgical techniques, anesthesia, and critical care have improved the surgical
TABLE 2. Surgical procedures

\begin{tabular}{lc}
\hline \multicolumn{1}{c}{ Variable } & Value \\
\hline Extent of graft replacement & \\
Total arch replacement & $736(73.1 \%)$ \\
Partial arch replacement & $28(2.8 \%)$ \\
Hemiarch replacement & $243(24.1 \%)$ \\
Concomitant procedure & \\
CABG & $186(18.5 \%)$ \\
Root replacement & $59(5.9 \%)$ \\
$\quad$ Composite graft & 47 \\
$\quad$ Aortic valve sparing & 12 \\
Aortic valve replacement & $85(8.4 \%)$ \\
Aortic valve repair & $2(0.2 \%)$ \\
Sinotubular junction plication & $63(6.3 \%)$ \\
Mitral valve replacement & $5(0.5 \%)$ \\
Mitral valve repair & $10(1.0 \%)$ \\
Tricuspid annuloplasty & $9(0.9 \%)$ \\
Maze & $6(0.6 \%)$ \\
Intraoperative variables & \\
Lower body circulatory arrest time (min) & \\
Selective cerebral perfusion time $(\mathrm{min})$ & $55.5 \pm 17.6$ \\
Myocardial ischemic time (min) & $129.4 \pm 67.0$ \\
Cardiopulmonary bypass time $(\mathrm{min})$ & $139.3 \pm 53.9$ \\
Moderate $\left(25^{\circ}\right.$-28 $\left.{ }^{\circ} \mathrm{C}\right)$ & \\
Deep (<25 C) & $529(52.5 \%)$ \\
\hline$C A B G$ Coronary artery bypass grafting; $H C A$, hypothermic circulatory arrest. \\
$\quad$
\end{tabular}

outcomes. Thus, antegrade SCP with HCA has achieved widespread acceptance as a reliable brain protection technique. ${ }^{1-4}$ Recent reports have suggested some refinement of surgical techniques, in addition to SCP, and have demonstrated lower mortality rates of $4 \%$ to $8 \%{ }^{4,11-15} \mathrm{~A}$ gradual increase of the core temperature during HCA from deep to moderate hypothermia has been encouraged to avoid deep hypothermia-associated coagulopathy and reduce the inflammatory substances associated with prolonged cardiopulmonary bypass. ${ }^{4,16}$ Our current basic management of the core temperature during HCA with SCP is moderate hypothermia, which has produced favorable outcomes in aortic arch surgery. ${ }^{17}$ However,

TABLE 3. Risk factors for in-hospital mortality

\begin{tabular}{lcccc}
\hline & \multirow{2}{*}{ Enivariate } & \multicolumn{4}{c}{ Multivariate } \\
\cline { 3 - 6 } \multicolumn{1}{c}{ Factor } & \multicolumn{1}{c}{$\boldsymbol{P}$ value } & $\boldsymbol{P}$ value & OR & $\mathbf{9 5 \%}$ CI \\
\hline Previous cardiac surgery & .063 & .234 & & \\
CAD & $<.001$ & .223 & & \\
COPD & .009 & .041 & 2.157 & $1.030-4.518$ \\
Liver dysfunction & .007 & .014 & 5.629 & $1.419-22.331$ \\
CKD (creatinine $>1.5 \mathrm{mg} / \mathrm{dL})$ & $<.001$ & $<.001$ & 4.637 & $2.392-8.988$ \\
Concomitant $\mathrm{CABG}$ & $<.001$ & $<.001$ & 3.424 & $1.837-6.382$ \\
Deep hypothermia $\left(<25^{\circ} \mathrm{C}\right)$ & .089 & .476 & & \\
\hline
\end{tabular}

$O R$, Odds ratio; $C I$, confidence interval; $C A D$, coronary artery disease; $C O P D$, chronic obstructive pulmonary disease; $C K D$, chronic kidney disease; $C A B G$, coronary artery bypass grafting. 
TABLE 4. Risk factors for permanent neurologic dysfunction

\begin{tabular}{lcccc}
\hline & Univariate & \multicolumn{4}{c}{ Multivariate } \\
\cline { 3 - 6 } \multicolumn{1}{c}{ Factor } & $\boldsymbol{P}$ value & $\boldsymbol{P}$ value & OR & $\mathbf{9 5 \%}$ CI \\
\hline Elderly $($ age $\geq 75 \mathrm{y})$ & .073 & .068 & & \\
CVD & $<.001$ & .002 & 3.374 & $1.589-7.162$ \\
CKD (creatinine $>1.5 \mathrm{mg} / \mathrm{dL})$ & .081 & .201 & & \\
Emergent surgery & .002 & $<.001$ & 4.013 & $1.887-8.535$ \\
Concomitant CABG & .044 & .006 & 3.119 & $1.379-7.057$ \\
\hline
\end{tabular}

$O R$, Odds ratio; $C I$, confidence interval; $C V D$, cerebrovascular disease; $C K D$, chronic kidney disease; $C A B G$, coronary artery bypass grafting.

deep hypothermia of about $22^{\circ} \mathrm{C}$, which has a great advantage for more secure brain, spinal cord, and visceral organ protection during HCA, is still used in selected higher risk patients with severe CVD and CKD or requiring a longer duration of HCA of the lower body because of anticipated difficulty in performing the distal anastomosis to the descending aorta. ${ }^{10}$

To the best of our knowledge, the present study is the largest scale study of open aortic arch replacement. The period of surgery was limited to 10 years, and a similar surgical technique-including SCP with RAxA perfusion-was used for all cases. Thus, we believe the outcome is worthy of assessment. The mortality rate of $4.7 \%$ is comparable to those of recent other reports, ${ }^{4,11-15}$ with a range of $4 \%$ to $9 \%$, although more than $70 \%$ of our patients underwent more extensive TAR and $25 \%$ were emergency cases. In addition, $15.5 \%$ of the patients were older than 80 years, and $24.4 \%$ required concomitant coronary or aortic root surgery. At least 10 surgeonsincluding some residents-were involved in the present series of arch repairs. In terms of the incidence of neurologic deficits, although the overall rate of $10.2 \%$ was similar, the stroke (PND) rate of 3.3\% was lower than those of other reports $(4 \%-7 \%)$. We believe our

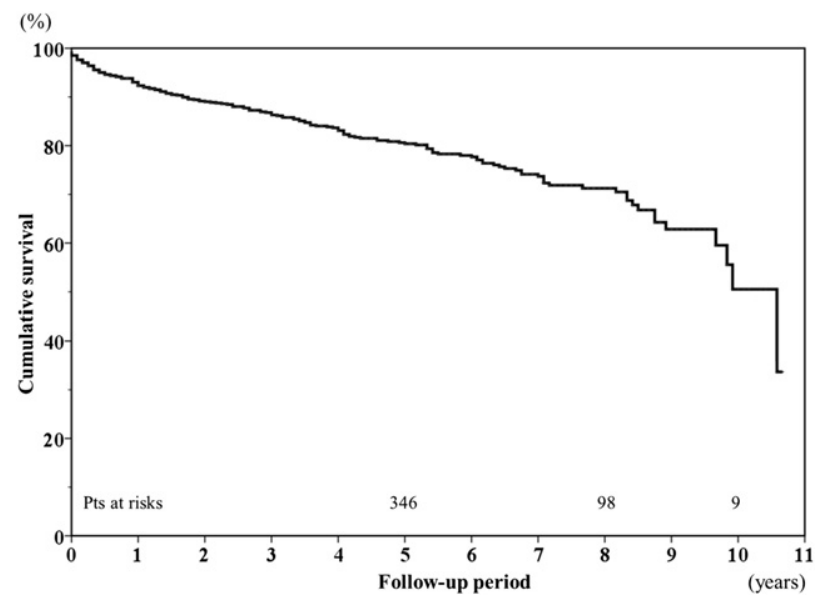

FIGURE 1. Survival curve for all patients by Kaplan-Meier method. Cumulative survival rate was $80.4 \%$ and $71.2 \%$ at 5 and 8 years, respectively. outcomes have been so satisfactory that our contemporary aortic arch replacement technique should be recognized as the standard repair for arch aneurysms.

With regard to risk factor analyses, the independent risk factors for early mortality were COPD, liver dysfunction, $\mathrm{CKD}$, and concomitant CABG. The number of in-hospital deaths from respiratory failure, in particular, interstitial pneumonia or pulmonary fibrosis, has recently increased with the increase in patient age. These serious complications seem to be untreatable after their occurrence postoperatively. For these patients, arch TEVAR should be recommended. Regarding $\mathrm{CKD}$ and concomitant $\mathrm{CABG}$, most such patients have more severe atherosclerosis and are critically compromised hosts, with diabetes and hemodialysis. For some of these patients, percutaneous coronary intervention before arch repair might be a good option to improve the outcome.

In terms of PND, CVD, emergency operation, and concomitant $\mathrm{CABG}$ were risk factors. The former 2 factors are easily recognized as risk factors for stroke. More meticulous brain protection with deep hypothermia is recommended for such conditions. A requirement for concomitant $\mathrm{CABG}$ is another risk factor for stroke. We believe this did not result from technical problems, but rather that these patients tended to have severe atherosclerotic vascular lesions, particularly in the aorta, arch vessels, or intracranial arteries, which might be related to the occurrence of stroke.

Regarding the technical aspect, our aortic arch repair technique has some characteristic features. The first is our routine use of RAxA perfusion by simple direct cannulation in the axilla. ${ }^{7}$ It can be established easily and quickly, even in an emergency setting, and can prevent the cerebral emboli caused by retrograde femoral artery perfusion. Rightsided SCP through the RAxA can also be quickly achieved by simple clamping of the innominate artery. The second characteristic strategy is a preference for the use of stepwise distal anastomosis with a mini- or standard elephant trunk insertion for easier and more secure anastomoses for TAR. ${ }^{8}$ The third technique is separate reconstruction of the arch vessels using a multibranched prosthetic graft for TAR. $^{2}$ We are encouraged to thoroughly remove the atheromatous arterial wall around the origin of the arch vessels and to perform the anastomosis at less atherosclerotic parts of the arch vessels, resulting in fewer embolic cerebrovascular events.

Long-term survival after open aortic arch repair has been demonstrated in some other reports. Kazui and colleagues ${ }^{2}$ reported an actuarial survival at 5 and 7 years of $79 \%$ and $77 \%$, respectively, and a recent report by Patel and colleagues ${ }^{12}$ demonstrated a 12 -year survival of $51.2 \%$. Their survival curves were similar to ours, with $80.4 \%$ and $71.7 \%$ survival at 5 and 8 years, respectively. The median patient age in the present series was 72 years, and some of our 

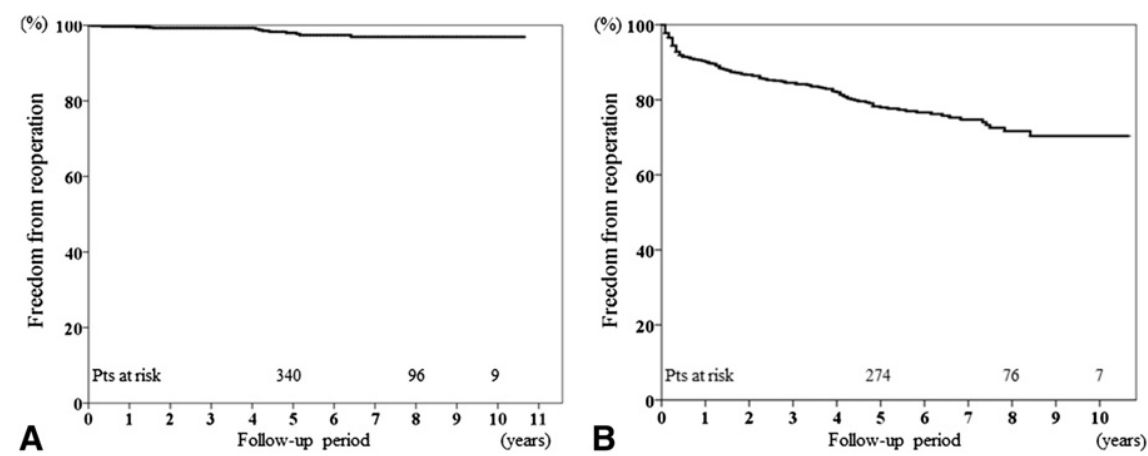

FIGURE 2. A, Kaplan-Meier analysis of freedom from reoperation related to initial arch repair. The rate of freedom from reoperation for the initially repaired arch segment was $98.0 \%$ and $96.9 \%$ at 5 and 8 years, respectively. B, Kaplan-Meier analysis of freedom from all aortic reoperation, including other segments. Freedom from late aortic surgery was $78.0 \%$ and $71.7 \%$ at 5 and 8 years, respectively.

patients died of cancer. Thus, we believe the long-term survival rate was acceptable in our patient cohort.

Furthermore, reoperation related to the initial arch repair during follow-up-for anastomotic false aneurysm or graft infection-was very rare. Most secondary aortic interventions after open arch repair were necessary for the other aortic lesions, including the aortic root, descending aorta, or abdominal aorta. For anastomotic false aneurysm, open repair or TEVAR can be successfully performed. In particular, TEVAR is easily applied to such limited lesions, with the proximal landing zone in the arch graft.

However, endovascular treatments have expanded in the past decade, and in 2008 some commercially available devices for TEVAR were introduced in Japan. Since then, our surgical strategy for aortic arch aneurysm has gradually shifted toward TEVAR. Currently, open aortic repair remains our basic surgical option, because it has been well established and has provided satisfactory early and long-term outcome. However, for its lesser invasiveness, this new surgical technique-including hybrid TEVAR-has been applied predominantly in limited high-risk patients, including the elderly ( $>75$ years old), patients with severe comorbidities (eg, impaired cardiac, pulmonary, liver, or renal function), and those with a history of previous cardiac surgery. ${ }^{18}$ Some reports of hybrid arch procedures have demonstrated an overall mortality rate of $3.2 \%$ to $11 \%$ and a stroke rate of $0 \%$ to $11 \%,{ }^{5,6,19,20}$ A recent metaanalysis of 463 patients who underwent hybrid arch surgery reported a 30-day mortality of $8.3 \%$ and an incidence of stroke and paraplegia of $4.4 \%$ and $3.9 \%$, respectively. ${ }^{21} \mathrm{Al}-$ though the study included high-risk patients unsuitable for conventional open aortic repair, the mortality was slightly greater rather than the current results of open arch surgery, including in our study. In addition, the meta-analysis had a mean follow-up period of 18.9 to 61 months, leaving the long-term results still unclear.

Several innovations in endovascular devices and techniques have occurred within the past few years. For instance, the chimney graft technique, involving the supra-aortic branches, which can treat up to zone 0 lesions without sternotomy, was recently introduced. Gehringhoff and colleagues ${ }^{22}$ reported their experience using this technique for aortic arch pathologic features in 9 patients. In that report, 1 patient $(11.1 \%)$ underwent surgical arch replacement because of a persistent type I endoleak, and 1 early death $(11.1 \%)$ occurred. However, the safety and durability of these new techniques remains unclear, and future studies are necessary.

Comparing the outcomes between open aortic repair and TEVAR is complicated by the patient selection bias. In general, arch TEVAR has been indicated for higher risk patients with severe comorbidities. Milewski and colleagues ${ }^{19}$ reported that hybrid arch procedures have their primary benefit in high-risk cases, especially elderly patients previously considered at prohibitively high risk to undergo conventional open arch repair. In the present analysis, the risk factors for early mortality were COPD, liver dysfunction, and CKD. We agree that arch TEVAR is a beneficial therapeutic option for patients expected to experience high mortality and morbidity with conventional open arch repair. However, we are skeptical about the adoption of this new technology for patients with a reasonable operative risk and younger patients, especially those with connective tissue disorders, because the mid- and long-term outcomes of TEVAR are still unclear. We have experienced extremely difficult and high-risk surgical conversion after TEVAR required for endoleak, infection, and esophageal fistula in some patients. These lessinvasive TEVAR repairs, including hybrid procedures, should still be applied predominantly in high-risk patients with advanced age or many comorbidities.

The present study had some limitations. It was a retrospective study of a single group of patients who underwent open aortic arch repair with SCP. To compare the results of the 2 surgical strategies more clearly, a multicenter, prospective, randomized study is required. 


\section{CONCLUSIONS}

A well-established contemporary open aortic arch repair using SCP with hypothermia produced satisfactory early and long-term outcomes and remains a standard therapy with good long-term durability. It is highly recommended, except for high-risk patients.

\section{References}

1. Bachet J, Guilmet D, Goudot B, Dreyfus GD, Delentdecker P, Brodaty D, et al. Antegrade cerebral perfusion with cold blood: a 13-year experience. Ann Thorac Surg. 1999;67:1874-8.

2. Kazui T, Washiyama N, Muhammad BA, Terada H, Yamashita K, Takinami M, et al. Total arch replacement using aortic arch branched grafts with the aid of antegrade selective cerebral perfusion. Ann Thorac Surg. 2000;70:3-9.

3. Kazui T, Yamashita K, Washiyama N, Terada H, Bashar AH, Suzuki K, et al. Aortic arch replacement using selective cerebral perfusion. Ann Thorac Surg. 2007;83:S796-8.

4. Zierer A, Detho F, Dzemali O, Aybek T, Moritz A, Bakhtiary F. Antegrade cerebral perfusion with mild hypothermia for aortic arch replacement: single-center experience in 245 consecutive patients. Ann Thorac Surg. 2011;91:1868-74.

5. Zhou W, Reardon M, Peden EK, Lin PH, Lumsden AB. Hybrid approach to complex thoracic aortic aneurysms in high-risk patients: surgical challenges and clinical outcome. J Vasc Surg. 2006;44:688-93.

6. Bavaria J, Milewski RK, Baker J, Moellaer P, Szeto W, Pochettino A. Classic hybrid evolving approach to distal arch aneurysms: toward the zone zero solution. J Thorac Cardiovasc Surg. 2010;140(6 Suppl):S77-80.

7. Numata S, Ogino H, Sasaki H, Hanafusa Y, Hirata M, Ando M, et al. Total arch replacement using antegrade selective cerebral perfusion with right axillary artery perfusion. Eur J Cardiothorac Surg. 2003;23:771-5.

8. Ogino H, Ando M, Sasaki H, Minatoya K. Total arch replacement using a stepwise distal anastomosis for arch aneurysms with distal extension. Eur J Cardiothorac Surg. 2006;29:255-7.

9. Sasaki H, Ogino H, Matsuda H, Minatoya K, Ando M, Kitamura S. Integrated total arch replacement using selective cerebral perfusion: a 6-year experience. Ann Thorac Surg. 2007;83:S805-10.

10. Ogino H, Sasaki H, Minatoya K, Matsuda H, Tanaka H, Watanuki H, et al. Evolving arch surgery using integrated antegrade selective cerebral perfusion: impact of axillary artery perfusion. J Thorac Cardiovasc Surg. 2008;136:641-9.
11. Halkos ME, Kerendi F, Myung R, Kilgo P, Puskas JD, Chen EP. Selective antegrade cerebral perfusion via right axillary artery cannulation reduces morbidity and mortality after proximal aortic surgery. J Thorac Cardiovasc Surg. 2009; 138:1081-9

12. Patel HJ, Nguyen C, Diener AC, Passow MC, Salata D, Deeb GM. Open arch reconstruction in the endovascular era: analysis of 721 patients over 17 years. J Thorac Cardiovasc Surg. 2011;141:1417-23.

13. Kulik A, Castner CF, Kouchoukos NT. Outcomes after total aortic arch replacement with right axillary artery cannulation and a presewn multibranched graft Ann Thorac Surg. 2011;92:889-97.

14. Thomas M, Li Z, Cook DJ, Greason KL, Sundt TM. Contemporary results of open aortic arch surgery. J Thorac Cardiovasc Surg. 2012;144:838-44.

15. Okada K, Omura A, Kano H, Sakamoto T, Tanaka A, Okita Y, et al. Recent advancements of total aortic arch replacement. J Thorac Cardiovasc Surg. 2012; 144:139-45.

16. Kamiya H, Hagl C, Kropivnitskaya I, Böthig D, Kallenbach K, Khaladj N, et al. The safety of moderate hypothermic lower body circulatory arrest with selective cerebral perfusion: a propensity score analysis. J Thorac Cardiovasc Surg. 2007; 133:501-9.

17. Minatoya K, Ogino H, Matsuda H, Sasaki H, Tanaka H, Kobayashi J, et al. Evolving selective cerebral perfusion for aortic arch replacement: high flow rate with moderate hypothermic circulatory arrest. Ann Thorac Surg. 2008; 86:1827-32

18. Murashita T, Matsuda H, Domae K, Iba Y, Tanaka H, Sasaki H, et al. Less invasive surgical treatment for aortic arch aneurysm in high-risk patients: a comparative study of hybrid thoracic endovascular aortic repair and conventional total arch replacement. J Thorac Cardiovasc Surg. 2012;143:1007-13.

19. Milewski RK, Szeto WY, Pochettino A, Moser GW, Moeller P, Bavaria JE. Have hybrid procedures replaced open aortic arch reconstruction in highrisk patients? A comparative study of elective open arch debranching with endovascular stent graft placement and conventional elective open total and distal aortic arch reconstruction. J Thorac Cardiovasc Surg. 2010;140: 590-7.

20. Ferrero E, Ferri M, Viazzo A, Robaldo A, Zingarelli E, Sansone F, et al. Is total debranching a safe procedure for extensive aortic-arch disease? A single experience of 27 cases. Eur J Cardiothorac Surg. 2012;41:177-82.

21. Koullias GJ, Wheatley GH III. State-of-the-art of hybrid procedures for the aortic arch: a meta-analysis. Ann Thorac Surg. 2010;90:689-97.

22. Gehringhoff B, Torsello G, Pitoulias GA, Austermann M, Donas KP. Use of chimney grafts in aortic arch pathologies involving the supra-aortic branches. J Endovasc Ther. 2011;18:650-5. 